\title{
Online Responses towards Parental Rearing Styles Regarding Hand-held Devices
}

\author{
Gretchen Geng \& Leigh Disney \\ Charles Darwin University, Australia
}

\begin{abstract}
This article reviewed the literature on parental rearing styles and used responses from an online discussion forum to investigate people's opinions towards parental rearing styles and strategies when children use hand-held devices. Critical discourse analysis (CDA) was used as an analysis method via micro, meso and macro multi-level interpretations. The majority of online responses agree that parents' positive engagement using an authoritative rearing style play an important role in children's use of hand-held devices, while authoritarian, permissive and uninvolved rearing styles hindered children's development. Five positive parenting strategies were promoted by online responses, which included accepting technology, managing the use of technology, being responsible for children's technology choice, setting playing time, and encouraging children to have no-technology time. Educators and parents who are interested in using hand-held devices with children will find this article useful in understanding positive strategies to implement when children use these devices.
\end{abstract}

Keywords: Hand-held devices; Parental rearing style; Children; Online responses

\section{Introduction}

We are undergoing the most rapid technological transformation in terms of information, and our children are being born into and growing in a digital age where by how they gather and interpret information is different to that of their parents and current educators (Palfrey \& Gasser, 2008).

Hand-held devices and software, such as tablets, smartphones and Nintendo DS, have been coopted into young children's playing and learning for a period of time. Many studies have been conducted about using them effectively in educational contexts so that their positive potential impact could be boosted. For example, in the studies conducted by Disney, Barnes, McDowall and Geng (2013), it was found that the use of an iPad could enhance young children's engagement in their learning and playing. Therefore, the use of hand-held devices is becoming more accepted in terms of a developmentally appropriate learning device used during children play time.

From a developmental perspective, experts believe that symbolic and imaginative play provides the foundations for all domains of development (Ebbeck \& Waniganayake, 2010). Gonzalez-Mena (2008) further justifies the use of play for children by explaining that play is a 'developmentally appropriate practice', in that it directly relates to children's stage of development as defined by theorists. Moreover, within early childhood settings 'play and learning are inextricably woven together; play is intrinsically motivated and powerful for 
children in all cultures' (Ebbeck \& Waniganayake, 2010, p. 5). Research clearly shows that play within the early years provides a meaningful and culturally responsive curriculum (Lim, 2009).

A good parenting practice enhances young children's cognitive, language, and social development during their play (Berk, 2013; Burchina, Vandergrift, \& Piantam 2010). Parents' positive attitudes, educational preparedness, and personal commitment to children's play can make them more verbally stimulating and sensitive to their children's needs whilst playing (Berk, 2013; Lamb \& Ahnert, 2006). Since the 1960s, Diana Baumrind and other researchers have studied parents interaction with their preschool children and promoted effective teaching approaches for parents, which include (a) acceptance of the child and involvement in the child's life, including fostering an emotional connection with children (Baumrind, 1971; Baumrind \& Black, 1967; Barber \& Olsen, 1997; Berk, 2013); (b) behavioral control of children by setting up rules and boundaries to promote more mature behavior (Berk, 2013; Gray \& Steinberg, 1999); and (c) autonomy granting, which encourages self-reliance (Berk, 2013; Hart, Newell, \& Olsen, 2003).

Berk (2013) discusses parents' four child rearing styles: (1) authoritative child rearing, (2) authoritarian child rearing, (3) permissive child rearing, and (4) uninvolved child rearing. The authoritative child rearing styles involves high acceptance and involvement, adaptive control strategies, and appropriate autonomy granting.

Authoritative parents are willing to accommodate to their children's perspective to increase the chance that their children listen to them (Kuczynski \& Lollis, 2002; Russell, Mize \& Bissaker, 2004). Children under authoritative rearing style are more competent, have high self-control abilities, task persistence, and high self-esteem (Amato \& Fowler, 2002; Berk, 2013; Gonzalez \& Wolters, 2006; Milevsky, Schlechter, Netter, \& Keehn, 2007). Moreover, they respond to their parents' views and have moral maturity (Berk, 2013). The authoritative parents (a) create a warm and welcoming environment for their children; (b) exercise firm and reasonable behavioral control through reasoning and promoting children's self-regulation; and (c) more importantly allow children to make decisions when children are ready or are willing to engage in joint decision making when possible (Amato \& Fowler, 2002; Berk, 2013; Gonzalez \& Wolters, 2006; Milevsky et al., 2007).

The authoritarian child rearing style uses high behavioral control and low autonomy granting, which causes children to be anxious, unhappy and have low self-esteem and self-reliance. Authoritarian parents often engage in psychological control which often interrupts children's ideas and decisions, resulting in children who tend to be anxious and withdrawn or aggressive (Hart et al, 2003; Kakihara, Titon-Weaver, Kerr, \& Stattin, 2010; Steinberg, Blatt-Eisengart, \& Cauffman, 2006; Thompson, Hollis, \& Richards, 2003).

The permissive child rearing style is highlighted by parents' allowing their children autonomous decision making regardless of whether or not they are capable of doing so or the developmental appropriateness of the child's decisions (Berk, 2013). Children of permissive parents tend to be impulsive, disobedient, and rebellious (Barber \& Olsen, 1997; Steinberg et al., 2006).

The uninvolved child rearing styles combines low acceptance and involvement with very limited behavioral control and general indifference to issues of autonomy, these parents fail to: engage in strategies to establish and enforce rules, model social behavior, listen to children's voice, monitor children's activities or provide guidance to children's choices (Aunola, Stattin, \& 
Nurmi, 2000; Schroeder et al., 2010). The uninvolved children display many problems including school achievement difficulties, depression, anger, and antisocial behavior (Aunola, Stattin, \& Nurmi, 2000; Berk, 2013; Schroeder, Bulanda, Giordano, \& Cernkovich, 2010).

Table 1 provides an overview of the four rearing styles with parents' care and the consequent children's developmental outcomes.

Table 1. Overview of Four Rearing Styles

\begin{tabular}{|l|l|l|}
\hline Child Rearing style & Parents' care & Children's developmental outcome \\
\hline Authoritative & $\begin{array}{l}\text { high acceptance and } \\
\text { involvement, adaptive control } \\
\text { strategies, and appropriate } \\
\text { autonomy granting }\end{array}$ & $\begin{array}{l}\text { more competent, have high self- } \\
\text { control abilities, task persistence, } \\
\text { and high self-esteem }\end{array}$ \\
\hline Authoritarian & $\begin{array}{l}\text { high behavioral control and low } \\
\text { autonomy granting }\end{array}$ & $\begin{array}{l}\text { anxious, unhappy and have low in } \\
\text { self-esteem and self-reliance }\end{array}$ \\
\hline Permissive & $\begin{array}{l}\text { allow children to make many } \\
\text { decisions by themselves at any } \\
\text { age no matter whether or not } \\
\text { they are capable of doing so }\end{array}$ & $\begin{array}{l}\text { impulsive, disobedient, and } \\
\text { rebellious }\end{array}$ \\
\hline Uninvolved & $\begin{array}{l}\text { low acceptance and } \\
\text { involvement with very limited } \\
\text { behavioral control and general } \\
\text { indifference to issue of } \\
\text { autonomy }\end{array}$ & $\begin{array}{l}\text { many problems including school } \\
\text { achievement difficulties, } \\
\text { depression, anger and antisocial } \\
\text { behavior }\end{array}$ \\
\hline
\end{tabular}

Clearly the optimal rearing style is authoritative, to promote an effective authoritative rearing style, Cipriano and Stifter (2010) and Kochanska, Philibert and Barry (2009) suggest parents use extra warmth and firm control in modifying children's maladaptive styles. Moreover, Nelson, Hart, Yang, Olsen and Jin (2006) and Rubin and Burgess (2002) emphasize that parents' encouragement can benefit inhibited children to be assertive and to express their autonomy. Parental monitoring of children's play promotes positive child behavior. It is known that the more parents know about their children's behaviors, the greater the decline in delinquency, leading to long-term positive outcomes (Laird, Pettit, Bates, \& Dodge, 2003). Therefore, the bidirectional relationship between parents and children becomes stronger based upon understanding and knowledge of each other's behaviors (Kuczynski, 2003). Moreover, children seem to understand parents' affection, appropriate control and respect for self-determination; parents who take these proactive steps to intervene in their children's actions can set strong parent-child relationships (Berk, 2013). That is to say, parents can monitor and build strong relationships between themselves and their children, even those who have developed antisocial acts and delinquency, through positive interaction and play scaffolded by an authoritative rearing style.

Within the new digital age, parents are utilizing emergent technologies to enhance and build on children's experiences and develop their own pedagogical practices or rearing styles (Colker, 2011). Their personal rearing styles in using these devices represent psychologically their own understandings, premises or propositions felt to be true (Richards, 2008). For example, some parents use these devices as an educational tool, while other parents overused them and these devices become in essence a "babysitting tool" (Chuan, 2002; Stewart, 2006). 
The use of technology as a babysitting tool is very commonly seen in parents' uninvolved and/or permissive rearing style. In these rearing styles, children are allowed to use the technologies, including both educational and non-educational technology, as much as they like. This then leads to children being exposed to material that is neither age appropriate nor suited to their developmental characteristics. In addition it is becoming more and more prevalent that parents regularly use hand-held devices themselves whilst supervising their children's play, this leads to limited engagement by the parent affecting relationships and knowledge of their child (Scott, 2014). In contrast, other parents were not embracing emergent technologies. Knight and Hunter (2013) discuss the reasons behind the lack of engagement which includes parents' fear of unknown technologies as well as their confusion as to whether these technologies could actually be beneficial for their children. The negative impact of technology use has been investigated by many researchers. Chuan (2002) mentioned that computer games had behavior influence on children's creativity, loneliness feeling, and learning passion. Conversely other researchers such as Chou and Lee (2012) stated that there were advantages of the application of iPad on children's play which include: respecting children's thinking, interactional learning, child engagement, and assistance in constructing children's meaningful knowledge. Researchers such as Kleopatra (2009) stated the manner in which children learn with hand-held devices, such as Apple's iPad allows for a different form of interactional learning with peers, parents and teachers that has potential for positive outcomes. This initiates a social parenting dilemma, parents who were aware of the negative impact from the overuse of technology are still inclined to ban the use of the technologies instead of understanding the positive advantages or value of the technologies and providing a balanced exposure. In Chou and Lee (2012)'s report about the application of iPad on children's playing, they stated that in order to guide children's healthy physical and psychological development, children and their parents need to understand the reasons why children enjoy using hand-held devices; moreover, with certain rules in place, children can not only hold strong interest in playing and learning but also experience the enjoyment and satisfaction in their development.

Thus, there is a need to investigate how parents can use strategies to promote the authoritative rearing styles so that a more positive learning and playing environment can be created for young children whilst using hand-held devices. This study, therefore, is to investigate parental rearing styles in facilitating young children's use of hand-held devices and promotion of positive learning and playing environments.

\section{Methods}

Although the online responses from the bulletin board or chat groups may not represent the general public opinions towards the use of hand-held devices in children's learning, the Internet-sourced data provides a map upon which various opinions and attitudes can be located and compared from different perspectives and concerns (Tamatea, 2008; 2010). This article is therefore to use online responses to investigate young children's parents' rearing styles and their strategies in promoting a positive impact on young children's development using hand-held devices.

An article within an online discussion platform about children's use of handheld devices served as the foundational literature for this research. The article attracted one hundred and twentyfive commenters who had access to the Internet and the online discussion to contribute to the 
discussion in relation to children's use of hand-held devices, the online discussion was viewed during February to May, 2014. The total 125 people were from around the world.

Out of the 125 responses, 35 (28\%) were parents of young children, while the rest were teachers or educators $(10.4 \%)$, medical practitioners $(7.2 \%)$ and teenage students $(2.4 \%)$ and some responders did not mention their occupation or if they had children. Two medical practitioners were also parents of old children (older than 12 years old).

This report used critical discourse analysis (CDA) (Tamatea, 2008) to analyze these online responses. CDA is based upon both linguistic theory (Ainsworth \& Hardy, 2004; Fairclough, 2001; Henderson, 2005; Wodak, 2001) and social theory (Habermans, 1990). CDA can be used to analyze data through a three-dimensional framework - micro, meso and macro-level interpretations about their opinions towards parents' rearing styles and strategies that could be used to assist young children's use of hand-held devices. The data is the opinion of the people who speak for or on behalf of themselves and who cared to contribute to the online discussion forum.

\section{Online Responses}

After conducting a CDA of the 35 parents' responses in relation to how they used hand-held devices within their children's play and learning it became clear that most of the parents were showing clear examples of or preferred to use an authoritative rearing style; it was also mentioned in some examples that parents were using an authoritarian rearing style. In all the online responses there was no example involving permissive or uninvolved rearing style.

Figure 1 shows an example of a parent using an authoritative rearing style when her son uses hand-held devices.

\footnotetext{
My son has had exposure to technology since he was 18 months old. He is now 6 years old and he knows how to operate a computer, an iPad, iphone, xbox, etc. Is he developmentally delayed? No. In fact, he is on the ball with his lessons. Is this because of his tech use? I don't think so. Is he an introvert? No, he loves playdates and making friends.

What does these "horrible devices" do for him? For one, I am responsible enough to supervise what he can and cannot do on these things. He is multi-national and apps like Freya and Friends or the Winston Show lets him get acquainted with different cultures and provides information from around the world. Does he get lost? On the contrary, he tends to come to us and discuss what he's seen or done. He has set hours of tech, more than what is recommended but he also has a life outside of "tech". More so, as parents, we take time to make sure we spend some time with him when he is using technology (eg., xBox, iPad, computer or TV). As a result, instead of embracing violence/sexfilled games or shows, he likes to watch or read National Geographic types of articles, and he cautions his playdates when they turn on the TV and wants to watch a non-age appropriate show.

I believe it is important, more so than cautioning against the use of technology by young children, to educate parents. These devices are not babysitters. Nor should they replace parental interaction or rule. Blaming technology for children's behavior gives parents an out for their own behaviors.

I have seen other parents buying their children iPads at a young age and then leave them to use it as they please. That I do not agree with. Do I believe these kids are more prone to tantrums and bratty behavior because of technology? I am more inclined to agree that these kids I know are spoiled rotten by their parents rather than blame the iPad or iPhone.
}

Figure 1. An Example of Online Parents' Responses Using Authoritative Rearing Style 
In this example, the parent has exposed her son to technology, rather than putting a strict authoritarian rearing style of not allowing her son to learn or play with hand-held devices. She demonstrates a clear acceptance of hand-held devices for her son. Moreover, she was involved by being "responsible to supervise" what her son can do and cannot do. This rearing style is completely different from a permissive rearing style, which allows children to decide freely what they would like to play no matter of developmental capacity. The parent demonstrates adaptive control strategies such as setting hours of technology/playdates for her son, as well as acknowledging her sons "life outside of tech". As a result, her son came to her to make decision collaboratively about what games or apps he should be playing (Berk, 2013; Amato \& Fowler, 2002; Gonzalez \& Wolters, 2006; Milevsky et al, 2007).

Although there were examples provided in the online responses that authoritative rearing style were used in parenting and guiding children's use of hand-held devices, it was shown in the online responses that there were a lot of confusion and misunderstanding about the best manner with which to parent in regards to children's use of hand-held devices. For example, out of the 35 parents' responses, there are three parents confused about whether or not their children should use and how to use hand-held devices in their children's learning and playing. The three parents were failing to engage in strategies to establish and enforce rules, monitor children's activities and provide guidance to children's choices. Interestingly only one out of the three parents were thinking about using a different rearing style for her child to benefit whilst playing with hand-held devices, while the other two parents were blaming the handheld devices so that the negative impact from the hand-held devices could be erased. For example, a parent from the online responses stated that her 4 year old started to have uncontrolled anger and tantrums after she started to use her mobile phone and she was constantly on Facebook, email, texting, etc. The mother was blaming herself for using her mobile phone, was worried about her modelling the opposite of what she would like to be as a "good parent"; and was very ready to get rid of the mobile phone. This parent's rearing style shows that she overused technology herself and "neglected" her child's needs, which caused her child to be angry and have antisocial behaviors (Aunola et al., 2000; Berk, 2013; Schroeder et al, 2010). This response also aligns with Scott's (2014) statement that parents who constantly engage with hand-held devices whilst supervising their children will have less personal knowledge and connections with their children.

Responses also show that some parents were advocating for an authoritarian rearing style, for example, the banning of technology to improve educational outcomes (see Figure 2).

My son has not being focusing in class during school. His grades are failing. Can it due to overuse of computer? I started to ban my son from using the computer until he can improve his grades. He is only allow to play when he has completed his work. Initially, he starts to throw tantrum, showing aggression, speaking rudely to me. He is addicted to computer games. Now, he can't even take out his toys to play. I am extremely worry of him. And wondering what next...????

Figure 2. An Example of Online Parents' Responses Using Authoritarian Rearing Style

In this example, the parent showed concern about her son's development because of the overuse of technology. This agrees with Chuan (2002)'s studying that computer games had behavior influence on children's creativity, loneliness feeling and learning passion. However, owing to the parent's fear (Knight \& Hunter, 2013) of the unknown technologies as well as her own confusion and worriedness of overuse she chose to use an authoritarian rearing style to provide strict limitations for her sons use of technology. This rearing style has a negative 
impact on her child that he is anxious, unhappy, low self-reliance, and the child is anxious and aggressive (Hart et al., 2003; Kakihara, Titon-Weaver, Kerr \& Stattin, 2010; Steinberg, BlattEisengart \& Cauffman, 2006; Thompson, Hollis \& Richards, 2003). The online responses show that this group of parents were worried that their rearing style is permissive or uninvolved (neglectful) (Chuan, 2002; Stewart, 2006); therefore, they intended to put strict control over their children's behavior, such as the complete banning of technological devices as a behavioral management tool to promote educational responsiveness (Chou\& Lee, 2012; Kleopatra, 2009).

Online responses suggested that technology should be controlled and monitored against children's outside play whilst also being used as a behavior management incentive. For example, "we require them (children) to go outside and play daily (weather permitting), and are not shy about removing 'technology' privileges as punishment for bad behavior or bad grades". However, some other responses also pointed out that it was not always practical for parents in current society to always promote outside play when dealing with their own busy schedules and own limited attention span. For example, a response states "I take my kids to the park. I enjoy watching them climb the ropes and slide the slides, but it is not a great source of entertainment. They can stay for over an hour. Unless I have a friend to shoot the breeze with my threshold is 10 minutes tops. Then I am watching the seconds widdle away". In coping with this dilemma, the other online responses provided many suggestions. For example, a response stated "technology needs to be managed... and making yourself available to your children for specified times during the day is a great attachment builder". Some other responses argued no matter that kind of tool the parent was to use, it was their parenting strategies that caused their son's behavioral issues. For example, a respondent stated "this is a world of technology. If we want to reach our kids in high school and college, we have to learn, understand, and embrace the technology they are growing up with"; and "positive parenting means tuning in to your child's developmental needs". These responses support the researchers' (e.g. Chou \& Lee, 2012) opinions that in order to guide children's healthy physical and psychological development, children and their parents need to understand the reasons why children enjoy using hand-held devices. Moreover, with certain rules in place, children should hold strong interest in playing and learning as well as experiencing the enjoyment and satisfaction from their development.

\section{Conclusion and Recommendation}

This article firstly reviewed four parental rearing styles: authoritative, authoritarian, permissive and uninvolved. Parents' care and their children's learning outcomes were also discussed. The study used 125 online responses and discussed the parent's rearing styles on young children's playing and learning with hand-held devices. It was shown by the responses that the authoritative rearing styles lead to successful examples of young children's play and learning with hand-held devices. Other than parents, other stakeholders from the total 125 online responses also contributed and discussed the useful strategies to promote the effective use of hand-held devices which linked closely to the authoritative parent rearing style to positively impact young children learning.

The positive parenting strategies include (a) accepting technology, (b) managing the use of technology, (c) being responsible for the children's choice technology while they are not developmentally capable, (d) allowing children to play and be ready to spend time playing with 
them when they approach the parents, and (e) setting playing time and also encouraging children to have no-technology time.

This study has its limitations. All the 125 responses were from those people who spoke on behalf of themselves and who cared to contribute online. Moreover, there was no experiment to investigate whether or not the positive strategies can significantly improve and promote children's learning outcomes from using hand-held devices.

Based upon this limitation, a further experiment will be developed to investigate parents' rearing styles in the context of young children playing hand-held devices. Moreover, parents' positive strategies and resources will be developed to assist young children's effective use of hand-held devices and promote parents' confidence and capabilities of using the devices appropriately themselves.

Although family issues (e.g. family sizes, employed parents, financial situation and single parent), child development issues (e.g. pre-mature baby, children with special needs) are challenging parents' parenting skills (Berk, 2013), all the online responses agreed that parents' positive engagement and using authoritative rearing style could play an important role in children's learning and playing with hand-held devices. One of the responses who worked with children with learning difficulties said "this sort of thinking is exactly the same as people being afraid of light-bulbs when they were first invented. Just because you fail to understand it, doesn't make it the devil's work".

Know your child, have an open mind, and give your child time to explore their interest, motivation and efficacy. Nothing works overnight!

\section{References}

Ainsworth, S. \& Hardy, C. (2004). Critical discourse analysis and identity: Why bother? Critical Discourse Studies, 1(2), 225-259.

Amato, P. R. \& Fowler, F. (2002). Parenting practices, child adjustment, and family diversity. Journal of Marriage and the Family, 64, 703-716.

Aunola, K., Stattin, H., \& Nurmi, J. E. (2000). Parenting styles and adolescents' achievement strategies. Journal of Adolescence, 23, 205-222.

Barber, B. K. \& Olsen, J. A. (1997). Socialization in context: Connection, regulation, and autonomy in the family, school, and neighbourhood, and with peers. Journal of Adolescent Research, 12, 287-315.

Baumrind, D. (1971). Current patterns of parental authority. Developmental Psychology Monograph, 4(1, Pt.2).

Baumrind, D. \& Black, A. E. (1967). Socialization practices associated with dimensions of competence in preschool boys and girls. Child Development, 38, 291-327.

Berk, L. E. (2009). Child development (8th ed.). Boston: Pearson/Allyn \& Bacon.

Berk, L. E. (2013). Child development (9th ed.). Boston: Pearson/Allyn \& Bacon.

Burchina, M., Vandergrift, N., \& Pianta, R. (2010). Threshold analysis of association between child care quality and child outcomes for low-income children in pre-kindergarten programs. Early Childhood Research Quarterly, 42, 166-176. 
Chuan, W. W.(2002) Research of elementary children's computing play behavior, creativity, and loneliness (Unpublished thesis). Child Welfare Department of Wen-hua College.

Chuo, M-J. \& Lee, H-C. (2012). The application of the iPad on children's play-based brain science theory, the International Journal of Organisational Innovation, 5(1), 296-308.

Cipriano, E. A. \& Stifter, C. A. (2010). Predicting preschool effortful control from toddler temperament and parenting behavior. Journal of Applied Developmental Psychology, 31, 221-230.

Colker, L., J. (2011). Technology and learning what early childhood educators have to say. Teaching Young Children, 4(3), 25-27.

Disney, L., Barnes, A., McDowall, J., \& Geng, G. (2013, November). Observation of children's engagement when playing iPads, Proceedings of 21st International Conference on Computers in Education (ICCE2013, pp. 602-607). Bali, Indonesia.

Ebbeck, M. \& Waniganayake, M. (2010). Perspectives on play in a changing world. In M. Ebbeck \& M. Waniganayake (Eds.), Play in early childhood education: Learning in diverse contexts (pp. 5-25). South Melbourne: Oxford University Press.

Fairclough, N. (2001). Critical discourse analysis as a method in social scientific research. In R. Wodak \& M. Meyer (Eds.), Methods of critical discourse analysis. London, UK: Sage.

Gonzalez, A.-L. , \& Wolters, C.A. (2006). The relation between perceived parenting practices and achievement motivation in mathematics. Journal of Research in Childhood Education, 21, 203-217.

Gonzalez-Mena, J. (2008). Foundations of early childhood education: Teaching children in a diverse society (4th ed.). New York: McGraw Hill.

Gray, M. R. \& Steinberg, L. D. (1999). Unpacking authoritative parenting: Reassessing a multidimensional construct. Journal of Marriage and the Family, 61, 574-587.

Habermas, J. (1990). Moral consciousness and communicative action (Trans. C. Lendart \& S. W. Nicholson). Cambridge, MA: MIT Press.

Hart, C. H., Newell, L. D., \& Olsen, S. F. (2003). Parenting skills and social-communicative competence in childhood. In J. O. Greene \& B. R. Burleson (Eds.), Handbook of communication and social interaction skills (pp. 753-797). Mahwah, NJ: Erlbaum.

Henderson, R. (2005). A Faircloughian approach to CDA: principled eclecticism or a method searching for a theory? Melbourne Studies in Education, 46(2), 9-24.

Kakihara, F. Tilton-Weaver, L., Kerr, M., \& Stattin, H. (2010). The relationship of parental control to youth adjustment: Do youths' feelings about their parents play a role? Journal of Youth and Adolescence, 39, 1442-1456.

Kleopatra, N. (2009). Early childhood educational software: Specific features and issues of localization. Early Childhood Education Journal, 35(2), 173-179.

Knight, K. \& Hunger, C. (2013). Using technology in service delivery to families, children and young people. Child Family Community Australia Paper No 17. Retrieved on 10 July 2014 from http://apo.org.au/files/Resource/AIFS_UsingTechnologyInServiceDeliveryTo FamiliesChildrenAndYoungPeople_Nov_2013.pdf 
Kochanska, G., Philibert. R. A., \& Barry, R. A. (2009). Interplay of genes and early mother-child relationship in the development of self-regulation from toddler to preschool age. Journal of Child Psychology and Psychiatry, 50, 1331-1338.

Kuzynski, L.(2003). Beyond bidirectionality. In L. Kuzynski (Ed.), Handbook of dynamics in parent-child relations (pp. 3-24). Thousand Oaks, CA: Sage.

Kuzynski, L. \& lollis, S. (2002). Four foundations for a dynamic model of parenting. In J. R. M. Gerris (Eds.), Dynamics of parenting. Hillsdale, NJ: Erlbaum.

Laird, R. D., Pettit, G. S., Bates, J. E., \& Dodge, K.A. (2003). Parents' monitoring-relevant knowledge and adolescents' delinquent behavior: Evidence of correlated developmental changes and reciprocal influences. Child Development, 74, 752-768.

Lamb, M. E. \& Ahnert, L. (2006). Nonparental child care: Context, concepts, correlates, and consequences. In K. A. Renninger \& I. E. Sigel (Eds.), Handbook of child psychology: Vol 4. Child psychology in practice ( $96^{\text {th }}$ ed., pp. 700-778). Hoboken, NJ: Wiley.

Lim, M.-Y. S. (2010). Reconsidering the play-work dichotomy in pedagogy. In M. Ebbeck \& M. Waniganayake (Eds.), Play in early childhood education: Learning in diverse contexts (pp. 141-156). South Melbourne: Oxford University Press.

Milevsky, A., Schlechter, M., Netter, S., \& Keehn, D. (2007). Maternal and paternal parenting styles in adolescents: Associations with self-esteem, depression, and life satisfaction. Journal of Child and Family Studies, 16, 39-47.

Nelson, D. A., Hart, C. H., Yang, C., Olsen, J.A., \& Jin, S. (2006). Aversive parenting in China: Associations with child physical and relational regression. Child Development, 77, 554572.

Palfrey, J. \& Gasser, U. (2008). Born digital: Understanding the first generation of digital natives. New York: Basic Books.

Richards, J. E. (2008). Attention in young infants: A developmental psychophysiological perspective. In C. A. Nelson \& M. Luciana (Eds.), Handbook of developmental cognitive neuroscience ( $2^{\text {nd }}$ ed., pp. 479-497). Cambridge, MA: MIT Press.

Rubin, K. H.\& Burgess, K. B. (2002). Parents of aggressive and withdrawn children. In M. Bornstein (Ed.), Handbook of parenting ( ${ }^{\text {nd }}$ ed., pp. 383-418). Hillsdale, NJ: Erlbaum.

Russell, A., Mize, J., \& Bissaker, K. (2004). Parent-child relationships. In P.K. Smith \& C.H. Hart (Eds.), Blackwell handbook of childhood social development (pp. 204-222). Malden, MA: Blackwell.

Schroeder, R. D., Bulanda, R. E., Giordano, P. C., \& Cernkovich, S. A. (2010). Parenting and adult criminality: An examination of direct and indirect effects by race. Journal of Adolescent Research, 25, 64-98.

Scott, J. (August 11, 2014). Comment: Parenting while distracted. The Washington Post. Retrieved on 21 August 2014 from http://www.sbs.com.au/news/article/2014/08/11/commentparenting-while-distracted

Steinberg, L. Blatt-Eisengart, I., \& Cauffman, E. (2006). Patterns of competence and adjustment among adolescents from authoritative, authoritarian, indulgent, and neglectful homes: A replication in a sample of serious juvenile offenders. Journal of Research on Adolescence, 16, 47-58. 
Stewart, D. W. (2006). Generational mentoring. Journal of Continuing Education in Nursing, 37(3), 113-120.

Tamatea, L. (2008). If robots R-US, who am I: Online "christian' responses to artificial intelligence. Culture and Religion: An Interdisciplinary Journal, 9(2), 141-160.

Tamatea, L. (2010). Artificial intelligence, networks, and spirituality. Zygon, 45(4), 979-1002.

Thompson, A., Hollis, C., \& Richards, D. (2003). Authoritarian parenting attitudes as a risk for conduct problems: Results of a British national cohort study. European Child and Adolescent Psychiatry, 12, 84-91.

Wodak, R. (2001). Methods of critical discourse analysis. London, UK. Sage.

Correspondence: Gretchen Geng, Senior Lecturer, School of Education, Charles Darwin University, Darwin, Northern Territory, Australia 